\title{
The subcellular organization of itaconate biosynthesis in Aspergillus terreus
}

\author{
Walter M. Jaklitsch, ${ }^{1}$ Christian P. KubiceK ${ }^{2}$ and Michael C. Scrutton ${ }^{1 *}$ \\ ${ }^{1}$ Department of Biochemistry, King's College London, Campden Hill Road, London W8 7AH, UK \\ ${ }^{2}$ Abteilung für Mikrobielle Biochemie, Institut für Biochemische Technologie und Mikrobiologie, TU Wien, \\ Getreidemarkt 9/1725, A-1060 Wien, Austria
}

(Received 13 August 1990; accepted 5 November 1990)

\begin{abstract}
A novel assay method for cis-aconitate decarboxylase (EC 4.1.1.6) has been developed. Differential centrifugation of cell-free extracts of $A$ spergillus terreus prepared by Novozyme treatment/nitrogen cavitation of itaconate-producing mycelia has shown that cis-aconitate decarboxylase, a key enzyme of itaconate biosynthesis, is localized exclusively in the cytosol. The intracellular localization and maximal activities of nine other enzymes putatively involved in itaconate biosynthesis were examined under both producing and non-producing growth conditions. Two striking differences between growth and production mycelia were observed: $(a)$ cis-aconitate decarboxylase was absent from growing mycelia, and $(b)$ aconitase activity was increased at least two-fold in production mycelia. No significant variations in the maximal activities or intracellular localization were observed for the other enzymes investigated. Mitochondrial and cytosolic isoenzymes of NADP: isocitrate dehydrogenase and malate dehydrogenase were detected by cellulose acetate strip electrophoretic analysis, whereas this analysis detected only single isoenzymes of aconitase and citrate synthase. We therefore propose that in itaconate accumulation cis-aconitate is synthesized in the mitochondrion and then transported to the cytosol where it is converted to itaconate by cis-aconitate decarboxylase.
\end{abstract}

\section{Introduction}

Certain strains of the filamentous fungus Aspergillus terreus produce the commercially important compound itaconic acid, but the pathway of biosynthesis of this organic acid is not clearly understood. Several studies have indicated that itaconate is formed from pyruvate as a primary precursor (Eimhjellen \& Larsen, 1955; Shimi \& Nour el Dein, 1962; Lal \& Bhargava, 1962; Nowakowska-Waszczuk, 1973; Bentley \& Thiessen, $1957 a, b, c)$. Hence, conversion of pyruvate to itaconate could occur by: $(a)$ the condensation of pyruvate with acetyl-CoA to yield citramalate, which is dehydrated to itaconate; $(b)$ the condensation of three molecules of acetyl-CoA to yield 1,2,3-tricarboxypropane, which is dehydrogenated to cis-aconitate and then decarboxylated to itaconate; or (c) the decarboxylation of cis-aconitate which is formed from citrate. The presence of cisaconitate decarboxylase, a key enzyme for pathways $(b)$

Abbreviations: DTE, dithioerythritol: MTT, 3-(4,5-dimethylthiazol2-yl)-2,5-diphenyltetrazolium bromide; PMS, phenazine methosulphate; PMSF, phenylmethylsulphonyl fluoride. and $(c)$ in cell-free extracts of $A$. terreus, has been shown by Bentley \& Thiessen $(1957 c)$. Evidence in favour of pathway (c) was provided by Winskill (1983), who showed that $\left[2-{ }^{14} \mathrm{C}\right]$ acetate is a much better precursor for itaconate formation than $\left[1-{ }^{14} \mathrm{C}\right]$ acetate and that more than $90 \%$ of the incorporated ${ }^{14} \mathrm{C}$ from $\left[2-{ }^{14} \mathrm{C}\right]$ acetate was located in the methylene carbon of itaconate.

However, little is known about the regulation of itaconate accumulation. The physiological conditions for this fermentation closely resemble those described for citrate accumulation (Lockwood, 1975). Therefore, as postulated by Kubicek (1988), strains of Aspergillus which produce itaconic acid may have a physiology similar to strains which accumulate citric acid but in addition possess $c i s$-aconitate decarboxylase. This postulate would be supported if, as shown in these studies, $(a)$ cis-aconitate decarboxylase was specifically induced under the conditions required for formation of itaconic acid and $(b)$ the subcellular compartmentation of the enzymes involved in conversion of pyruvate to itaconic acid in $\boldsymbol{A}$. terreus resembled that described previously for conversion of pyruvate to citric acid in $A$. niger (Kubicek, 1988; Bercovitz et al., 1990) 


\section{Methods}

Organism and growth conditions. Aspergillus terreus NRRL 1960 (from CBS, Baarn, The Netherlands) was maintained on the synthetic agar medium described by Winskill (1983). The maximal level of itaconate synthesis was decreased tenfold if $\mathrm{NaCl}$ was omitted from the medium.

For growth experiments, spores were inoculated directly into $500 \mathrm{ml}$ (in 2 litre baffled flasks) of a medium which contained $20 \mathrm{~g}$ glucose, $5 \mathrm{~g}$ $\left(\mathrm{NH}_{4}\right)_{2} \mathrm{SO}_{4}, 3 \mathrm{~g} \mathrm{KH}_{2} \mathrm{PO}_{4}, 1 \mathrm{~g} \mathrm{MgSO}_{4} .7 \mathrm{H}_{2} \mathrm{O}, 0.4 \mathrm{~g} \mathrm{CaSO}_{4} .2 \mathrm{H}_{2} \mathrm{O}$, $1.88 \mathrm{mg} \mathrm{FeCl}_{3}, 0.55 \mathrm{mg} \mathrm{ZnSO}_{4} .7 \mathrm{H}_{2} \mathrm{O}$ and $0.12 \mathrm{mg} \mathrm{CuSO}_{4} .5 \mathrm{H}_{2} \mathrm{O}$ per litre. The $\mathrm{pH}$ prior to sterilization was 6.4 . Growth was obtained by incubation for $18-22 \mathrm{~h}$ at $33^{\circ} \mathrm{C}$ on a Gallenkamp orbital shaker run at 160 r.p.m.

For experiments under conditions of itaconate formation, the mycelium was grown for $24-25 \mathrm{~h}$ as described above, and was then separated from the growth medium by gentle suction filtration, washed with sterile distilled water, and incubated at $33^{\circ} \mathrm{C}$ and 160 r.p.m. in $500 \mathrm{ml}$ of a production medium. This latter medium contained $100 \mathrm{~g}$

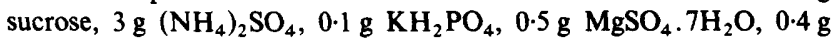
$\mathrm{CaSO}_{4} \cdot 2 \mathrm{H}_{2} 0,3.77 \mathrm{mg} \mathrm{FeCl}, 1 \cdot 1 \mathrm{mg} \mathrm{ZnSO}_{4} .7 \mathrm{H}_{2} \mathrm{O}$ and $0.24 \mathrm{mg}$ $\mathrm{CuSO}_{4} \cdot 5 \mathrm{H}_{2} \mathrm{O}$ per litre. The $\mathrm{pH}$ prior to sterilization was $2 \cdot 1$. The initial mycelium concentration in this production medium was in the range of $2 \cdot 5-2 \cdot 8 \mathrm{~g}$ dry weight $1^{-1}$. The biomass concentration increased up to $14 \mathrm{~h}$ and was thereafter constant at $10 \pm 1 \mathrm{~g}$ dry weight $1-1$, the $\mathrm{pH}$ of the medium was constant at $1.65 \pm 0 \cdot 1$. After $14 \mathrm{~h}$ in this medium the itaconate concentration was $1.3 \mathrm{~g}^{-1}$ and thereafter increased at a constant rate of $0.5 \pm 0.05 \mathrm{~g}^{-1} \mathrm{~h}^{-1}$ for $17-32 \mathrm{~h}$.

Cell disruption. For characterization of the cis-aconitate decarboxylase assay and for measurement of enzyme levels, cell-free extracts were prepared by sonication. Mycelium was harvested by suction filtration, washed with distilled water, squeezed dry and then ground in liquid nitrogen. The powder was suspended in $2 \mathrm{ml}$ (per $\mathrm{g}$ mycelium) of $0.1 \mathrm{M}-$ potassium phosphate $\mathrm{pH} 6.4$ containing $1 \mathrm{~mm}$-phenylmethylsulphonyl fluoride (PMSF) and $1 \mathrm{mM}$-dithioerythritol (DTE). The resulting suspension was sonicated for $15-25 \times 35 \mathrm{~s}$ in ice and centrifuged at $27000 \mathrm{~g}$ and $4{ }^{\circ} \mathrm{C}$ for $20 \mathrm{~min}$, yielding a cell-free extract which contained 14-17 mg protein $\mathrm{ml}^{-1}$ (growing mycelium) or 3-11 $\mathrm{mg} \mathrm{ml}^{-1}$ (itaconate-producing mycelium).

Preparation of cell-free extract containing intact intracellular organelles. The procedure used is a modification of that described by Osmani \& Scrutton (1985). Mycelium was harvested after 19-22 h growth, or at 16-19 $\mathrm{h}$ after change of medium (itaconate producing mycelium), by filtration through muslin and was then washed with distilled water. Ten grams of washed mycelium were shaken at $30^{\circ} \mathrm{C}$ for $35 \mathrm{~min}$ in $60 \mathrm{ml}$ $0.2 \mathrm{M}$-potassium phosphate $\mathrm{pH} 6.4$ containing $0.6 \mathrm{M}$-mannitol (phosphate/mannitol buffer) and $4 \mathrm{mg}$ Novozyme $234 \mathrm{ml}^{-1}$. The treated mycelium was filtered through muslin and then washed with $100 \mathrm{ml}$ phosphate/mannitol buffer and followed by either $300 \mathrm{ml}$ Tris/sucrose buffer (10 mM-Tris/HCl pH 7.5, 0.25 M-sucrose, $2 \mathrm{mM}-\mathrm{MgCl}_{2}, 1 \mathrm{mM}$ EDTA and $4 \mu \mathrm{M}$-PMSF) or $300 \mathrm{ml}$ phosphate/sucrose buffer ( $20 \mathrm{mM}$ potassium phosphate $\mathrm{pH} 6 \cdot 4,0 \cdot 25 \mathrm{M}$-sucrose, $1 \mathrm{~mm}$-EDTA and $4 \mu \mathrm{M}$ PMSF). The washed mycelium was suspended in $40 \mathrm{ml}$ Tris/sucrose or phosphate/sucrose buffer also containing $0.5 \mathrm{mM}$-DTE and $0.2 \%(\mathrm{w} / \mathrm{v})$ bovine serum albumin (cavitation buffer) and equilibrated with $\mathrm{N}_{2}$ at $5 \mathrm{MPa}$ and $4{ }^{\circ} \mathrm{C}$ for $35 \mathrm{~min}$ in a Parr cell disruption bomb. Cell debris was removed by filtration through muslin and centrifugation at $750 \mathrm{~g}$ and $4{ }^{\circ} \mathrm{C}$ for $10 \mathrm{~min}$. The resulting cell-free extract was centrifuged at $45000 \mathrm{~g}$ and $4{ }^{\circ} \mathrm{C}$ for $25 \mathrm{~min}$ to yield a supernatant, which is designated as the cytosolic fraction, and a pellet, which was resuspended in $2.5 \mathrm{ml}$ cavitation buffer to give a mitochondrial fraction.

Preparation of samples for cellulose acetate electrophoresis. Cell-free extracts and subcellular fractions were prepared as described above but using $0.03 \%(\mathrm{w} / \mathrm{v})$ bovine serum albumin in the cavitation buffer. The cell-free extract and the mitochondrial fraction were sonicated for
$6 \times 20 \mathrm{~s}$ in ice to disrupt intracellular organelles. For studies on $\mathrm{NADP}^{+}$: isocitrate dehydrogenase and aconitase the cell-free extract was centrifuged after sonication at $35000 \mathrm{~g}$ and $4^{\circ} \mathrm{C}$ for $15 \mathrm{~min}$ to remove debris. Aliquots $(1 \mathrm{ml})$ of the supernatant and the cytosolic fraction were concentrated 5-10-fold using Centricon C30 microconcentrators (Amicon). Concentration was achieved by centrifugation at $3000 \mathrm{~g}$ and $4{ }^{\circ} \mathrm{C}$ for $50 \mathrm{~min}$.

Analytical methods. Enzyme assays were performed within $8 \mathrm{~h}$ of cell disruption. Enzyme activities are expressed as $\mu \mathrm{mol}$ substrate converted or product formed per min.

cis-Aconitate decarboxylase was assayed by measuring the formation of labelled itaconate from $\left[1,5 \cdot{ }^{14} \mathrm{C}\right] \mathrm{citrate}$. The assay system contained,

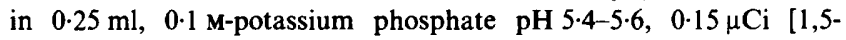
${ }^{14} \mathrm{C}$ citrate $\left(110 \mathrm{mCi} \mathrm{mmol}^{-1}, 4070 \mathrm{MBq} \mathrm{mmol}{ }^{-1}\right.$; Amersham) and $8 \mathrm{~mm}$-citrate. For assay in cell-free extracts, except for those prepared by $\mathrm{N}_{2}$ cavitation in phosphate/sucrose buffer, addition of aconitase gave no increase in activity since the extract already contained adequate levels of this enzyme. After incubation at $37^{\circ} \mathrm{C}$ the reaction was terminated by addition of $30 \mu \mathrm{l}$ concentrated $\mathrm{HCl}$ and denatured protein was removed by centrifugation at $12000 \mathrm{~g}$. Carrier itaconate $(0.1 \mu \mathrm{mol}$ per $\mu \mathrm{l}$ of supernatant fraction) was added and itaconic acid was separated by thin-layer chromatography on silica gel 60 (Merck) using ether/benzene/formic acid/water (21/9/7/2, by vol.) as developing solvent. The spots were visualized with bromcresol green, scraped, and eluted with $0.25 \mathrm{ml} 50 \mathrm{~mm}$-potassium phosphate $\mathrm{pH} 7$ from the silica gel. The ${ }^{14} \mathrm{C}$ content was quantified by liquid scintillation counting. Enzyme activity was calculated on the basis that the specific radioactivity in itaconate is half of that in citrate added.

Aconitase was assayed by measuring the increase in absorbance at $240 \mathrm{~nm}$ using an absorption coefficient of $4.88 \mathrm{~mm}^{-1} \mathrm{~cm}^{-1}$. The assay system contained, in $1 \mathrm{ml}, 0 \cdot 1 \mathrm{M}$-HEPES $\mathrm{pH} 7.4$ and $18 \mathrm{~mm}$-citrate.

Pyruvate carboxylase activity was determined as described by Osmani et al. (1981). NADH oxidation unrelated to oxaloacetate formation was suppressed by $0.03 \%(v / v)$ Triton X-100 in the assay mixture.

All other enzymes were assayed as described previously (Osmani \& Scrutton 1983, 1985), but Nonidet P40 was replaced by $0.025 \%(\mathrm{v} / \mathrm{v})$ Triton X100.

Protein was determined using the procedure described by Bradford (1976).

Itaconic acid was estimated in the culture filtrate as described by Bentley \& Thiessen $(1957 b)$. The background reactivity of this method was determined using the culture filtrate of $24 \mathrm{~h}$ growth mycelium and did not exceed an equivalent of $45 \mathrm{mg}$ itaconate $1^{-1}$.

For dry weight determinations mycelium was washed with distilled water and acetone, and dried at $80^{\circ} \mathrm{C}$ to constant weight.

Cellulose acetate electrophoresis and detection of enzyme activities. The techniques were as described by Osmani \& Scrutton (1983) except for aconitase. The composition of electrophoresis buffers is given in the respective figure legend. For aconitase the enzymic activity was visualized using two procedures. In method A, conversion of citrate to isocitrate was detected in the presence of isocitric dehydrogenase with formazan formation from 3-(4,5-dimethylthiazol-2-yl)-2,5-diphenyltetrazolium bromide (MTT) resulting from the oxidation of NADPH. The activity stain contained $6 \mathrm{mM}$-citrate, $5 \mathrm{mM}-\mathrm{MgCl}_{2}, 0.5 \mathrm{mM}$ NADP, $1 \mathrm{mM}$-EDTA, 0.7 $\mathrm{U}$ isocitric dehydrogenase (Sigma) $\mathrm{ml}^{-1}$, 100 mM-HEPES pH 7.4, 0.1\% Agar Noble (Difco), $0 \cdot 1 \mathrm{mg} \mathrm{MTT} \mathrm{ml}^{-1}$ and $0.1 \mathrm{mg}$ phenazine methosulphate (PMS) $\mathrm{ml}^{-1}$. In method $\mathrm{B}$, conversion of cis-aconitate to citrate was detected in the presence of citrate lyase and citrate synthase with the coenzyme A liberated being detected using the PMS/MTT system. In addition to the principal components (agar, MTT, PMS as in method A) the stain contained $2.5 \mathrm{mM}$-cis-aconitate, $0.35 \mathrm{~mm}$-acetyl-CoA, $0.4 \mathrm{U}$ citrate lyase $\mathrm{ml}^{-1}$ (Sigma) and $0.4 \mathrm{U}$ citrate synthase $\mathrm{ml}^{-1}$ (Sigma). 


\section{Results}

Characteristics of the cis-aconitate decarboxylase assay.

In order to validate the novel radioactive assay described here for determination of cis-aconitate decarboxylase activity, some properties of the enzyme were defined using cell-free extracts prepared by sonication of itaconate-producing mycelia, and in some cases were compared to the results obtained by Bentley \& Thiessen $(1957 c)$ using a manometric assay procedure.

Linear relationships were obtained between $\left[{ }^{14} \mathrm{C}\right]$ itaconate formation and either time of incubation (up to $120 \mathrm{~min}$ ) or enzyme concentration (up to $3 \mathrm{mg}$ protein $\mathrm{ml}^{-1}$ ). These relationships indicate that the aconitase activity present in the cell-free extract is sufficient to equilibrate citrate and cis-aconitate, hence producing the substrate required for the decarboxylase.

The dependence of cis-aconitate decarboxylation on $\mathrm{pH}$ was determined in $0.1 \mathrm{M}$-succinate, phosphate, and Tris buffers over the range $\mathrm{pH} 4 \cdot 0-8 \cdot 0$. Optimal activity was obtained at pH 5.5-5.9, in agreement with Bentley \& Thiessen $(1957 c)$.

For citrate the overall ' $K_{\mathrm{m}}$ ' was determined as $1.45 \pm 0.3 \mathrm{mM}$ (mean $\pm \mathrm{SEM}$, three determinations). This value can be calculated as equivalent to a $K_{\mathrm{m}}$ of $60 \mu \mathrm{M}$ for cis-aconitate on the basis of the equilibrium constant for aconitase (Thomson et al., 1966). At the citrate concentration $(8 \mathrm{mM})$ used in the routine assay the enzyme therefore exhibits approximately $85 \%$ of its maximal activity. Higher citrate concentrations were not employed due to dilution of the added $\left[{ }^{14} \mathrm{C}\right]$ citrate. The citrate concentration of cell-free extracts $(0.1-0.4 \mathrm{mM})$ was taken into consideration in the calculation of enzyme activities.

Enzyme activity was unaffected by addition of $5 \mathrm{~mm}$ DTE, $10 \mathrm{mM}$-EDTA, $100 \mu \mathrm{M}-\mathrm{Fe}^{3+}, 25 \mu \mathrm{M}-\mathrm{Cu}^{2+}, 25 \mu \mathrm{M}-$ $\mathrm{Zn}^{2+}$, or $25 \mu \mathrm{M}-\mathrm{Mn}^{2+}$ to the assay mixture. Addition of $10 \mathrm{mM}-\mathrm{Mg}^{2+}$ caused $50 \%$ inhibition. When the cell-free extract was desalted using a Pharmacia PD-10 column (equilibrated with $0.1 \mathrm{M}$-potassium phosphate $\mathrm{pH} \mathrm{6.4)}$ the specific activity was only slightly reduced. Hence significant levels of low molecular-mass effectors of the decarboxylase are not present in the cell-free extract.

\section{Subcellular localization of the enzymes involved in itaconate biosynthesis}

The subcellular distribution of enzymes involved in itaconate formation was determined both under growth conditions (Fig. 1 $a$ ) and under conditions of itaconate production (Fig. $1 b$ ). In Fig. 1 the results are expressed in the form recommended by de Duve et al. (1955). In all cases the recovery of activity in the mitochondrial and cytosolic fractions was in the range $94-110 \%$ of that present in the cell-free extract thus indicating that the analysis was valid.

Apart from the absence of cis-aconitate decarboxylase activity in growing mycelia the results obtained for both physiological states are similar. Typical mitochondrial marker enzymes such as 2-oxoglutarate dehydrogenase, pyruvate dehydrogenase, and $\mathrm{NAD}^{+}$: isocitrate dehydrogenase, were exclusively recovered in the mitochondrial fraction. Citrate synthase and aconitase, however, showed substantial activities in both the mitochondrial and cytosolic fractions.

cis-Aconitate decarboxylase, pyruvate carboxylase, and the cytosolic marker glucose-6-phosphate dehydrogenase were primarily located in the cytosolic fraction. The mitochondrial fraction contained less than $5 \%$ of the total activity of these enzymes and addition of $0.025 \%$ $(v / v)$ Triton X-100 caused no change in the level of activity. Centrifugation of the cytosolic fraction at $100000 \mathrm{~g}$ for $1 \mathrm{~h}$ did not remove any cis-aconitate decarboxylase activity.

The results shown in Fig. 1 were obtained using the Tris/sucrose buffer described in Methods. However, in the cell-free extract prepared by Novozyme treatment $/ \mathrm{N}_{2}$ cavitation in this buffer the total activity of $\mathrm{cis}$ aconitate decarboxylase was approximately $10 \%$ of that obtained when the cell-free extract was prepared by sonication in $0.1 \mathrm{M}$-potassium phosphate $\mathrm{pH} 6.4$ (see Table 1). Substitution of the phosphate/sucrose buffer for the Tris/sucrose buffer in the $\mathrm{N}_{2}$ cavitation studies gave a total activity comparable with that obtained by sonication but did not alter the distribution of cisaconitate decarboxylase activity and that of the other enzymes between the mitochondrial and cytosolic fractions. However, in the phosphate/sucrose buffer mitochondrial stability appeared to be improved since there was a significant decrease in the level of both citrate synthase and aconitase in the cytosolic fraction (data not shown).

The appearance of significant levels of citrate synthase and aconitase in the cytosolic fraction also raised the possibility that these activities indicated the presence of true cytosolic isoenzymes rather than an artifactual presence due to mitochondrial breakage during preparation. In order to examine this possibility we analysed the fractions for the presence of such isoenzymes by cellulose acetate strip electrophoresis and also performed such studies on $\mathrm{NAD}^{+}$:malate dehydrogenase, which has previously been shown to exhibit unique mitochondrial and cytosolic isoenzymes in $A$. nidulans (Osmani \& Scrutton, 1983). The results of such analyses are summarized in Fig. 2. It is clear that cytosolic and mitochondrial isoenzymes of $\mathrm{NAD}^{+}$:malate dehydro- 
(a)
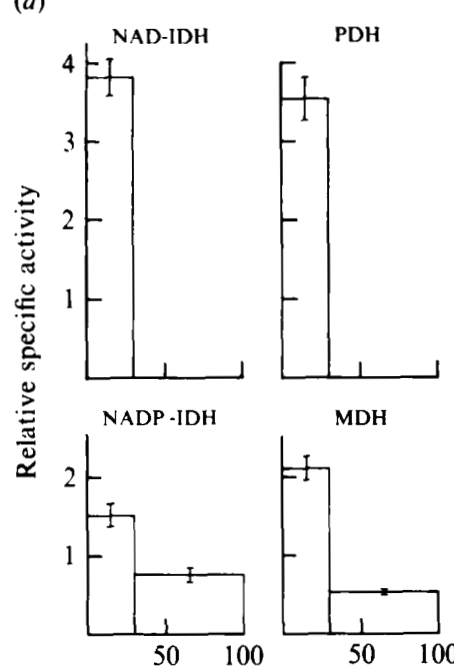

MDH
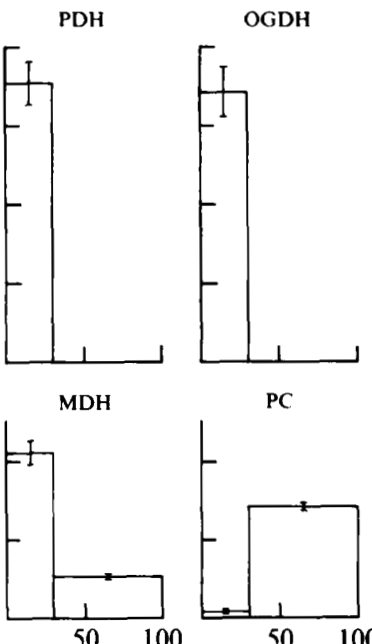

PC
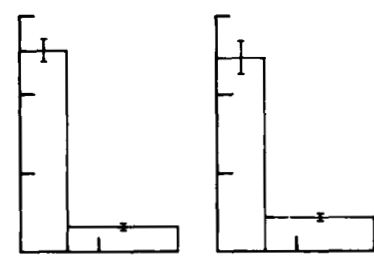

G6PDH

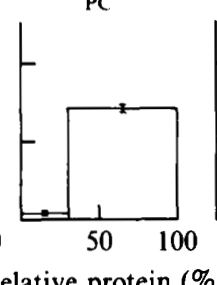

Relative protein (\%)

(b)
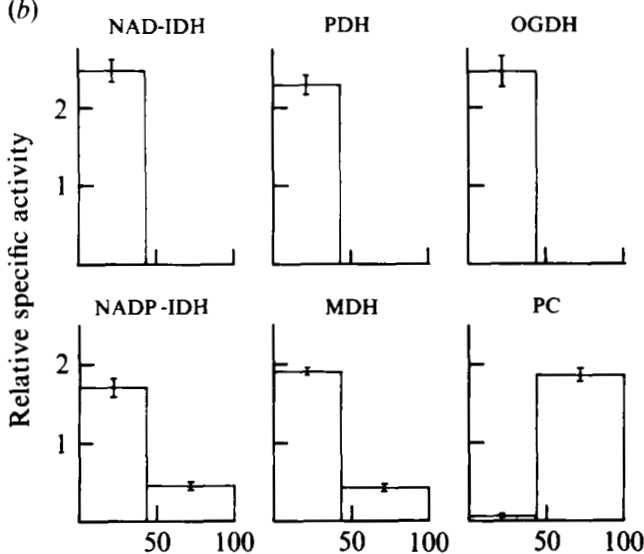

PC
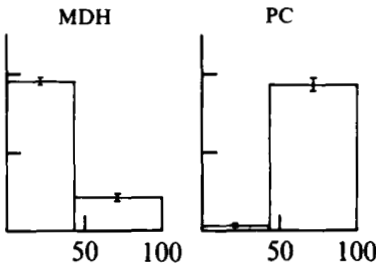

Relative protein (\%)

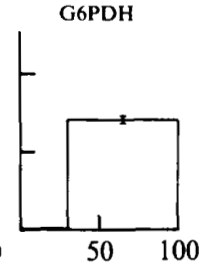

CS

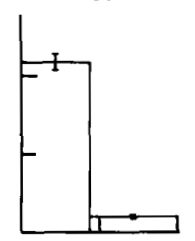

G6PDH

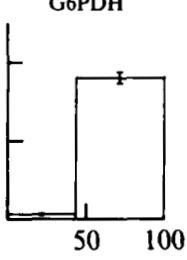
\%)
Aco

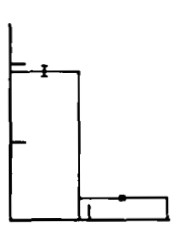

CAD

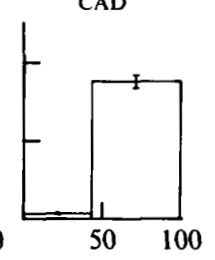

Fig. 1. Subcellular distribution of certain enzymes in $A$. terreus mycelia in the growth phase $(a)$ and under conditions of itaconate production (b). Cell-free extracts and subcellular fractions were prepared, and enzyme activities determined, as described in Methods. The results obtained are plotted as relative specific activities (units $\mathrm{mg}^{-1}$ in the fraction divided by units $\mathrm{mg}^{-1}$ in the cell-free extract) against relative protein. The left bar of each plot represents the mitochondrial fraction, the right bar shows the cytosolic fraction. All data are given as means \pm SEM of at least four (a) or six (b) experiments. Abbreviations used: NAD-IDH, NAD:isocitrate dehydrogenase; PDH, pyruvate dehydrogenase; OGDH, 2oxoglutarate dehydrogenase; $\mathrm{CS}$, citrate synthase; Aco, aconitase; NADP-IDH, NADP : isocitrate dehydrogenase; MDH, NAD:malate dehydrogenase; PC, pyruvate carboxylase; G6PDH, glucose-6-phosphate dehydrogenase; CAD, cis-aconitate dehydrogenase. The specific activities determined for these enzymes in the cell-free extract are given as the figures in parentheses in Table 1. genase and also of $\mathrm{NADP}^{+}:$isocitrate dehydrogenase are present in itaconate-producing $A$. terreus but that this organism contains only a single and identical aconitase species in both the mitochondrial and cytosolic fractions when electrophoresis was performed at $\mathrm{pHs}$ ranging from 6.3 to 7.5 , whether the activity was measured for the conversion of citrate to isocitrate or for the conversion of $c i s$-aconitate to citrate. Similarly a single and identical species of citrate synthase was detected in these fractions (data not shown).

\section{Enzyme levels in growing and itaconate-producing $A$. terreus mycelia}

We examined the specific activities of the enzymes involved in itaconate biosynthesis from the pyruvate level in cell-free extracts prepared from growth-phase and production-phase mycelia. These studies were designed to investigate the mechanisms which may be responsible for diversion of carbon flow towards organic acid accumulation under production conditions. The data which are summarized in Table 1 were obtained using cell-free extracts prepared by sonication, but for comparison the figures in parentheses in Table 1 show the specific activities obtained in cell-free extracts prepared by Novozyme treatment/ $\mathbf{N}_{2}$ cavitation. Little difference in the specific activities of the enzymes is observed between the extracts prepared from the growthphase and production-phase mycelia except for cisaconitate decarboxylase, which appears only in the production phase, and aconitase, which is at least two times higher in the production-phase mycelium. In the context of previous studies on the biosynthesis of citric acid and itaconic acid it is of particular interest that no significant differences were observed for the specific activities of $\mathrm{NAD}^{+}$: or NADP+ : isocitrate dehydrogenase or of 2-oxoglutarate dehydrogenase. Since the protein concentrations of the cell-free extracts prepared from 

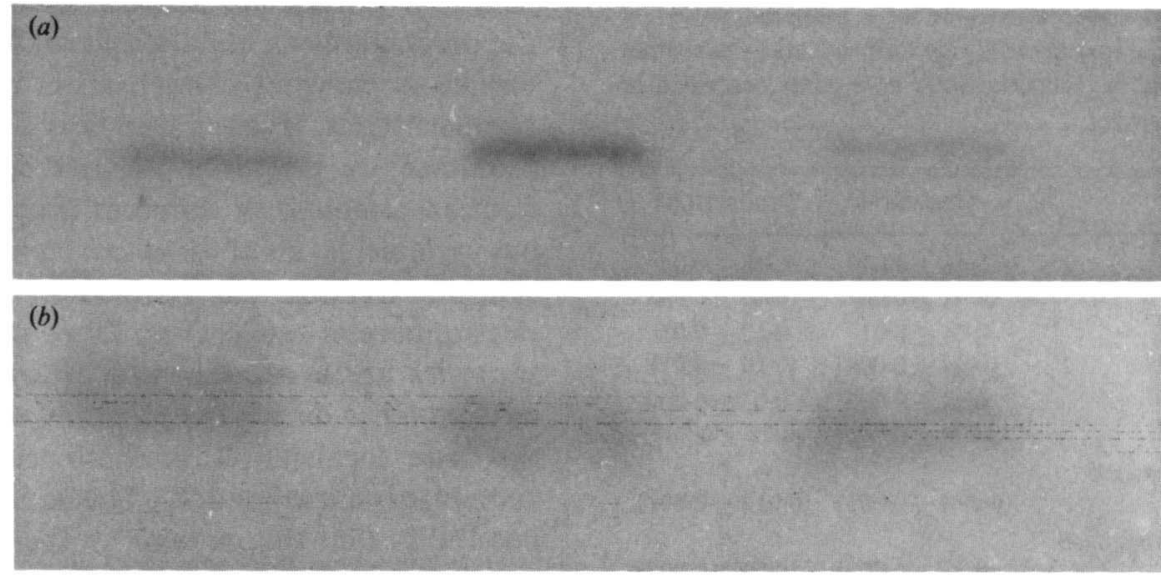

(c)

(d)

Fig. 2. Electrophoretic analysis of various enzymes in cell-free extracts and subcellular fractions prepared from itaconate-producing mycelia. (a) Aconitase visualized by method A, (b) aconitase visualized by method B (see Methods), (c) NAD ${ }^{+}$: malate dehydrogenase, $(d)$ NADP $^{+}$:isocitrate dehydrogenase. The electrophoresis buffer was 19 mM-potassium phosphate, pH 6.5 (a,c), pH 6.3 (b), and pH $5.7(d)$. The cytosolic fraction was loaded on track 1, the cell-free extract on track 2, and the mitochondrial fraction on track 3.

growth-phase and production-phase mycelia were comparable, the specific activities shown in Table 1 are indicative of the relative behaviour of the total enzyme activities in these mycelia.

\section{Discussion}

This report provides further confirmation that $A$. terreus under conditions of itaconic acid production contains all the enzymes required for conversion of pyruvate to itaconate via reactions of the tricarboxylic acid cycle. Enzymes such as pyruvate dehydrogenase, pyruvate carboxylase, citrate synthase, and $\mathrm{NAD}^{+}$: malate dehydrogenase are present at significant levels in growthphase mycelia and also at comparable levels in mycelia which produce itaconic acid (Table 1). The maximal activity of aconitase increases significantly under conditions of itaconic acid production in these mycelia, which also contain cis-aconitate decarboxylase, an enzyme that is absent from growth-phase mycelia. Hence $\boldsymbol{A}$. terreus exhibits a pattern of response with respect to changes in maximal enzyme activities which is comparable to that observed in other aspergilli which produce organic acids under conditions of imbalanced nutrition. For example oxalic acid production by $\boldsymbol{A}$. niger is associated with induction of oxaloacetate hydrolase (Kubicek et al., 1988) and malic acid production with a marked increase in the maximal activity of $\mathrm{NAD}^{+}$: malate dehydrogenase (Peleg et al., 1988). These increases in the relevant enzyme levels presumably facilitate formation of the appropriate organic acid end product. However, overproduction of citric and itaconic acids has also been postulated to require a decrease in metabolism of citrate via the tricarboxylic acid cycle, and decreases in the maximal activities of $\mathrm{NADP}^{+}$: isocitrate dehydrogenase and of 2-oxoglutarate dehydrogenase have been reported under such conditions (Winskill, 1983; Kubicek \& Röhr, 
Table 1. Enzyme activities in cell-free extracts prepared from growth- and production-phase A. terreus

Mycelia were grown and cell-free extracts were prepared either by sonication or by Novozyme treatment/ $\mathbf{N}_{2}$ cavitation (data in parentheses) as described in Methods. Enzymes were assayed as described in Methods.

\begin{tabular}{lcc}
\hline \hline Enzyme & Growth* & Production $\dagger$ \\
\hline Citrate synthase & $0.48 \pm 0.07$ & $0.48 \pm 0.04$ \\
& $(0.47 \pm 0.04)$ & $(0.40 \pm 0.04)$ \\
Aconitase & $0.04 \pm 0.01$ & $0.12 \pm 0.01$ \\
& $(0.04 \pm 0.004)$ & $(0.10 \pm 0.01)$ \\
Pyruvate dehydrogenase & $0.02 \pm 0.003$ & $0.03 \pm 0.002$ \\
& $(0.04 \pm 0.005)$ & $(0.03 \pm 0.003)$ \\
2-Oxoglutarate dehydrogenase & $\vdots$ & \pm \\
NAD ${ }^{+}$: isocitrate dehydrogenase & $(0.014 \pm 0.001)$ & $(0.012 \pm 0.001)$ \\
& $(0.03 \pm 0.002)$ & $(0.03 \pm 0.003)$ \\
NADP ${ }^{+}$:isocitrate dehydrogenase & $0.07 \pm 0.01$ & $0.10 \pm 0.01$ \\
& $(0.11 \pm 0.01)$ & $(0.11 \pm 0.01)$ \\
NAD ${ }^{+}$:malate dehydrogenase & $13.0 \pm 0.3$ & $14.0 \pm 0.6$ \\
& $(18.7 \pm 1.9)$ & $(12.4 \pm 0.4)$ \\
Glucose-6-phosphate dehydro- & & \\
genase & $0.38 \pm 0.07$ & $0.51 \pm 0.05$ \\
& $(0.63 \pm 0.08)$ & $(0.32 \pm 0.03)$ \\
Pyruvate carboxylase & $0.03 \pm 0.002$ & $0.03 \pm 0.008$ \\
& $(0.02 \pm 0.002)$ & $(0.02 \pm 0.001)$ \\
cis-Aconitate decarboxylase & 0 & $0.03 \pm 0.002$ \\
& $(0)$ & $(0.03 \pm 0.004)$ \\
& & $(0.003 \pm 0.001) \S$ \\
\hline \hline
\end{tabular}

* Mycelium was harvested after 19-22 h growth; enzyme activities are given as mean \pm SEM of three (sonication) or at least four (cavitation) different experiments.

$\dagger$ Mycelium was harvested 16-36 h (sonication) or 16-19 h (cavitation) after change of medium; enzyme activities are given as mean \pm SEM of at least five different experiments.

$\ddagger$ Data not given since these enzymes were inactivated by sonication. $\S$ In the Tris/sucrose buffer.

1978). Our studies, however, have failed to show any decrease in the maximal levels of either of these two enzymes, or of $\mathrm{NAD}^{+}$:isocitrate dehydrogenase in mycelia producing itaconic acid (Table 1). Our studies also demonstrate that no marked change in the distribution of $\mathrm{NADP}^{+}$:isocitrate dehydrogenase activity between the mitochondrial and cytosolic fractions occurs in association with the initiation of itaconic acid production (Fig. 1). Hence at the level of maximal enzyme activities mechanisms are apparent which would enhance conversion of citrate to itaconate but we have failed to identify changes which would decrease metabolism of citrate via the tricarboxylic acid cycle and hence divert flow away from this metabolic pathway.

Our data support the postulated subcellular organization of itaconate formation from pyruvate shown in Fig. 3. The data of Fig. 1 show clearly that pyruvate dehydrogenase is exclusively localized in the mitochondrion and pyruvate carboxylase exclusively in the cytosol while $\mathrm{NAD}^{+}$:malate dehydrogenase is present in both the mitochondrion and the cytosol due to the presence of unique isoenzymes characteristic of these two cellular compartments (Figs 1 and 2). Citrate synthase and aconitase are primarily localised in the mitochondrial fraction although in different preparations significant, but variable, levels of these two enzymes are found in the cytosolic fraction. On the basis of the cellulose acetate electrophoresis results (Fig. 2) we infer that these latter activities are a consequence of artifactual damage of mitochondria during the preparative procedure and that the true localization of both citrate synthase and aconitase is mitochondrial. The data of Fig. 2 exclude the possibility that the increase in the maximal activity of aconitase in itaconate-producing mycelia is due to appearance in the cytosol of an aconitase isoenzyme capable of interconverting citrate and cis-aconitate. It therefore seems reasonable to propose, as shown in Fig. 3 , that under conditions of itaconic acid production carbon leaves the mitochondrion in the form of cisaconitate and is then converted to itaconate in the cytosol. The mechanism by which cis-aconitate export is achieved remains to be determined. One possibility, which is illustrated in Fig. 3, is that this tricarboxylic acid is transported by the malate/citrate antiport, although given the relative concentrations of citrate and cis-aconitate which will be present, this antiport would have to possess a markedly higher affinity for cisaconitate than for citrate for significant cis-aconitate transport to occur under these conditions. An alternative possibility is that imbalanced nutrition causes induction of a different carrier system with selectivity for cisaconitate.

The subcellular localization of enzymes shown here for $A$. terreus and the mechanism proposed for intracellular metabolic organization of itaconate biosynthesis are markedly similar to those previously proposed for primary metabolism in $A$. nidulans (Osmani \& Scrutton, 1983) and for citrate biosynthesis in $A$. niger (Kubicek 1988). Most notably our studies indicate that pyruvate carboxylase is exclusively localized in the cytosol in $A$. terreus, in accord with the previous observation of such a localization in $A$. nidulans and with the predominant cytosolic localization of this enzyme in most strains of $A$. niger (Bercovitz et al., 1990). They do not accord with the report of Purohit \& Ratledge (1988) that pyruvate carboxylase is exclusively localized in the mitochondrion in certain strains of $A$. niger, although subsequent studies have failed to confirm this observation (Bercovitz et al., 1990).

W.M.J. was supported during these studies by the Fonds für Forderung Wissenschaftlicher Forschung. 


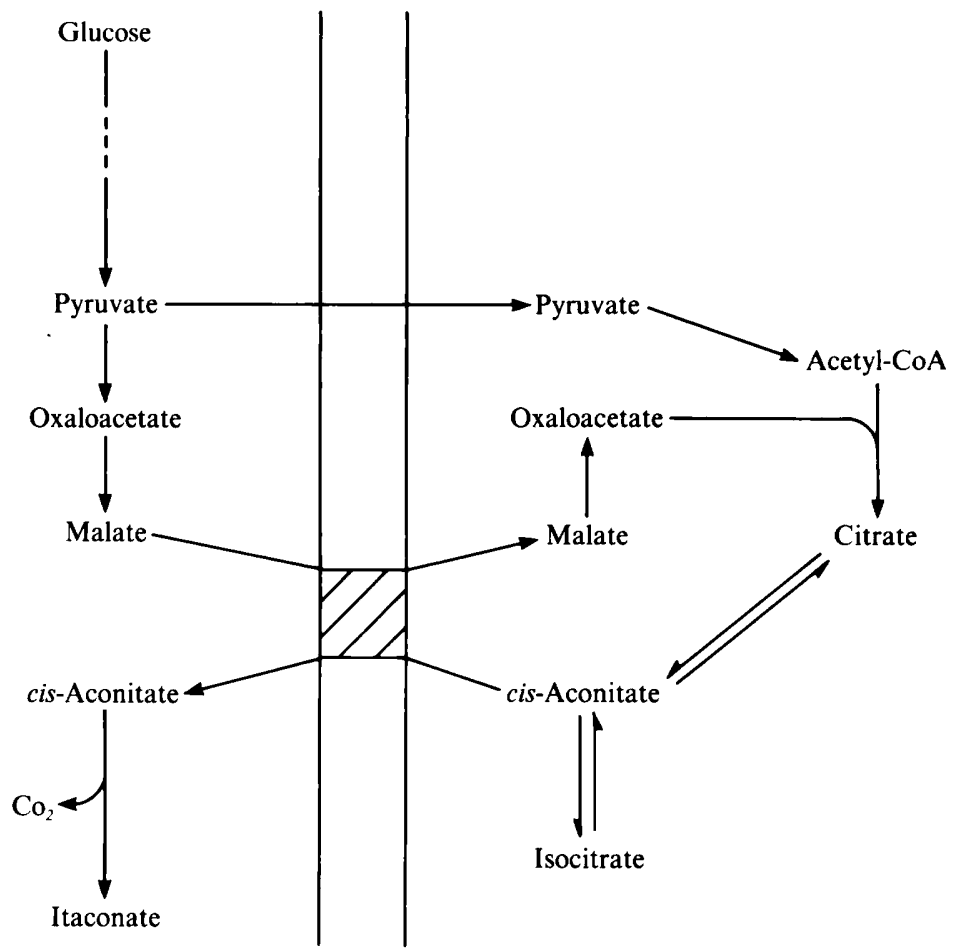

Fig. 3. Proposed subcellular organization of itaconate biosynthesis.

\section{References}

Bentley, R. \& Thiessen, C. P. (1957a). Biosynthesis of itaconic acid in Aspergillus terreus. I. Tracer studies with ${ }^{14} \mathrm{C}$-labelled substrates. Journal of Biological Chemistry 226, 673-687.

BeNTLEY, R. \& THIESSEN, C. P. (1957b). Biosynthesis of itaconic acid in Aspergillus terreus. II. Early stages in glucose dissimilation and the role of citrate. Journal of Biological Chemistry 226, 689-701.

BENTLEY, R. \& THIESSEN, C. P. (1957c). Biosynthesis of itaconic acid in Aspergillus terreus. III. The properties and reaction mechanism of cis-aconitic decarboxylase. Journal of Biological Chemistry 226, 703720.

Bercovitz, A., Peleg, Y., Battat, E., Rokem, J. S. \& Goldberg, I. (1990). Localization of pyruvate carboxylase in organic acidproducing Aspergillus strains. Applied and Environmental Microbiology 56, 1594-1597.

BRADFORD, M. M. (1976). A rapid and sensitive method for the quantitation of microgram quantities of protein utilizing the principle of protein-dye binding. Analytical Biochemistry 72, 248254.

de Duve, C., Pressman, B. C., Gianetto, R., Wattiaux, R. \& Appelmans, F. (1955). Tissue fractionation studies. 6. Intracellular distribution patterns of enzymes in rat-liver tissue. Biochemical Journal 60, 604-617.

EimHJellen, K. E. \& LaRSEN, H. (1955). The mechanism of itaconic acid formation by Aspergillus terreus. II. The effect of substrates and inhibitors. Biochemical Journal 60, 139-147.

KUBICEK, C. P. (1988). The role of the citric acid cycle in fungal organic acid fermentations. Biochemical Society Symposia 54, 113-126.

KubiceK, C. P. \& RöHR, M. (1978). The role of the tricarboxylic acid cycle in citric acid accumulation by Aspergillus niger. European Journal of Applied Microbiology and Biotechnology 5, 263-271.

KubiceK, C. P., Schreferl-Kunar, G., WöHrer, W. \& RöHr, M. (1988). Evidence for a cytoplasmic pathway of oxalate biosynthesis in Aspergillus niger. Applied and Environmental Microbiology 54, 633637.
LAL, M. \& Bhargava, P. M. (1962). Reversal by pyruvate of fluoride inhibition in Aspergillus terreus. Biochimica et Biophysica Acta 58, 628-630.

Lockwood, L. B. (1975). Organic acid production. In The Filamentous Fungi, vol. I, pp. 151-157. Edited by J. E. Smith, \& D. R., Berry, London: Edward Arnold.

NoWAKOWSKA-WASZCZUK, A. (1973). Utilization of some tricarboxylic acid cycle intermediates by mitochondria and growing mycelium of Aspergillus terreus. Journal of General Microbiology 79, 19-29.

Osmani, S. A. \& Scrutron, M. C. (1983). The sub-cellular localisation of pyruvate carboxylase and of some other enzymes in Aspergillus nidulans. European Journal of Biochemistry 133, 551-560.

OSMANI, S. A . \& SCRUTTON, M. C. (1985). The sub-cellular localisation and regulatory properties of pyruvate carboxylase from Rhizopus arrhizus. European Journal of Biochemistry 147, 119-128.

Osmani, S. A., Marston, F. A. O., Selmes, I. P., Chapman, A. G. \& SCRUtTon, M. C. (1981). Pyruvate carboxylase from Aspergillus nidulans. Regulatory properties. European Journal of Biochemistry 118, 271-278.

Peleg, Y., Stieglitz, B. \& Goldberg, I. (1988). Malic acid accumulation by Aspergillus flavus. I. Biochemical aspects of acid biosynthesis. Applied Microbiology and Biotechnology 28, 69-75.

PuRohit, H. J. \& Ratledge, C. (1988). Mitochondrial location of pyruvate carboxylase in Aspergillus niger. FEMS Microbiology Letters 55, 129-132.

Shimi, I. R. \& Nour el Dein, M. S. (1962). Biosynthesis of itaconic acid by Aspergillus terreus. Archiv für Mikrobiologie 44, 181-188.

Thomson, J. F., Nance, S. L., Bush, K. J. \& Szczepanik, P. A. (1966). Isotope and solvent effects of deuterium on aconitase. Archives of Biochemistry and Biophysics 117, 65-74.

WINSKILL, N. (1983). Tricarboxylic acid cycle activity in relation to itaconic acid biosynthesis by Aspergillus terreus. Journal of General Microbiology 129, 2877-2883. 